IZA DP No. 5484

Status-Seeking in Criminal Subcultures and the Double Dividend of Zero-Tolerance

Robert Dur

Joël J. van der Weele

February 2011 


\title{
Status-Seeking in Criminal Subcultures and the Double Dividend of Zero-Tolerance
}

\author{
Robert Dur \\ Erasmus University Rotterdam, \\ Tinbergen Institute, CESifo and IZA \\ Joël J. van der Weele \\ Goethe University Frankfurt
}

\section{Discussion Paper No. 5484 \\ February 2011}

\author{
IZA \\ P.O. Box 7240 \\ 53072 Bonn \\ Germany \\ Phone: +49-228-3894-0 \\ Fax: +49-228-3894-180 \\ E-mail: iza@iza.org
}

\begin{abstract}
Any opinions expressed here are those of the author(s) and not those of IZA. Research published in this series may include views on policy, but the institute itself takes no institutional policy positions.

The Institute for the Study of Labor (IZA) in Bonn is a local and virtual international research center and a place of communication between science, politics and business. IZA is an independent nonprofit organization supported by Deutsche Post Foundation. The center is associated with the University of Bonn and offers a stimulating research environment through its international network, workshops and conferences, data service, project support, research visits and doctoral program. IZA engages in (i) original and internationally competitive research in all fields of labor economics, (ii) development of policy concepts, and (iii) dissemination of research results and concepts to the interested public.
\end{abstract}

IZA Discussion Papers often represent preliminary work and are circulated to encourage discussion. Citation of such a paper should account for its provisional character. A revised version may be available directly from the author. 
IZA Discussion Paper No. 5484

February 2011

\section{ABSTRACT \\ Status-Seeking in Criminal Subcultures and the Double Dividend of Zero-Tolerance ${ }^{*}$}

This paper offers a new argument for why a more aggressive enforcement of minor offenses ('zero-tolerance') may yield a double dividend in that it reduces both minor offenses and more severe crime. We develop a model of criminal subcultures in which people gain social status among their peers for being 'tough' by committing criminal acts. As zero-tolerance keeps relatively 'gutless' people from committing a minor offense, the signaling value of that action increases, which makes it attractive for some people who would otherwise commit more severe crime. If social status is sufficiently important in criminal subcultures, zero-tolerance reduces crime across the board.

JEL Classification: K14, K42

Keywords: $\quad$ status concerns, street crime, subcultures, penalties, zero-tolerance, broken windows policing

Corresponding author:

Robert Dur

Erasmus University

Erasmus School of Economics/H 8-15

P.O. Box 1738

3000 DR Rotterdam

The Netherlands

E-mail: dur@ese.eur.nl

\footnotetext{
* We gratefully acknowledge comments on an earlier version by two anonymous referees, an associate editor, Josse Delfgaauw, Jeffrey Fagan, Chaim Fershtman, Stefano Ficco, Patricia Funk, Gerrit de Geest, Amihai Glazer, Maarten Goos, Vladimir Karamychev, Panu Poutvaara, Mikael Priks, Hein Roelfsema, Otto Swank, Ben Vollaard, seminar audiences in Amsterdam and Rotterdam, and participants to the 2006 CESifo Area Conference on Public Sector Economics in Munich and the 2006 Econometric Society European Meeting in Vienna. We thank Veerle Witte for making the Figure.
} 


\section{Introduction}

The 'zero-tolerance' or 'broken windows' approach to crime fighting holds that a more aggressive enforcement of minor offenses leads to a reduction in both minor offenses and more severe crime. This approach, first articulated by Wilson and Kelling (1982), has been pursued in New York City in the nineties and, since then, in several other US cities including Boston, Chicago, and Los Angeles. Although the effectiveness of zero-tolerance policies in fighting severe crime is still open to debate (see for instance Levitt (2004), Weisburd and Eck (2004), and Harcourt and Ludwig (2006)), a growing body of empirical evidence indicates that zero-tolerance indeed generates a double dividend. For instance, using cross-sectional data of US cities, Sampson and Cohen (1988), MacDonald (2002), and Kubrin et al. (2010) find a significant negative effect of police activity aimed at disorderly conduct on robbery rates, which can only be partly attributed to the indirect effect of zero-tolerance on the probability of arrest for robbery. Braga et al. (1999) conduct a randomized field experiment in Jersey City, New Jersey, and find that policing disorder has a negative effect on crime incidents, with little evidence of displacement to other areas. Corman and Mocan (2005) use monthly time-series data between 1974 and 1999 from New York City and find - after controlling for several potentially confounding variables including police presence and crime-specific arrests - support for negative effects of stricter enforcement of minor offenses on more severe crime. Funk and Kugler (2003) and Vollaard (2006) obtain similar results using Swiss and Dutch data, respectively.

The prevailing explanation for a double dividend of zero-tolerance relies on the idea that the ubiquity of disorder and minor crimes signals a general tolerance towards crime. In the words of former New York City mayor Rudolph W. Guiliani: "There's a continuum of disorder. Obviously murder and graffiti are two vastly different crimes. But they are part of the same continuum, and a climate that tolerates one is more likely to tolerate the other." ${ }^{1}$ One version

\footnotetext{
${ }^{1}$ See the Archives of Rudolph W. Giuliani, Major Addresses, "The Next Phase
} 
of this idea is that prevalence of minor crime signals a lax enforcement of crime more generally. The recent evidence in Lochner (2007) is not supportive of this signaling argument. Using longitudinal survey data for the US, he finds that young males' beliefs about the probability of arrest for various crimes are not affected by local neighborhood conditions like general lawlessness and disarray.

A slightly different version of this idea stresses the role of community-norms in criminal behavior (Ferrer (2010)). Kahan (1997) argues that the persistence of disorders and other minor crimes shows that the community is unwilling or unable to exert social sanctions and that crime is accepted as a social norm. This debate is still wide-open (e.g. Sampson and Raudenbush (2004), Rosado (2008)), but there is some evidence that casts doubt on the social-norm-signaling explanation of broken windows. Harcourt and Ludwig (2006) use data from relocation programs, and show that people who are randomly moved to better socio-economic neighborhoods (with different social norms) do not commit significantly less crime.

In this paper, we offer a new argument for a double dividend of zero-tolerance policies that holds even if public tolerance of crime is common knowledge. We argue that the incidence of minor and severe crimes is linked, not because it communicates hidden information about arrest rates or community attitudes, but because minor and severe crimes are interdependent strategies to attain status. To this end, we develop a model in which criminal behavior is, at least partly, motivated by social status concerns. In particular, we assume that individuals in criminal subcultures care about their status for being 'tough.' Individuals differ in innate toughness, which may reflect differences in nerve, physical fitness, or sensitivity to guilt. Tougher individuals have an absolute advantage in crime as well as a comparative advantage in more severe crime. Importantly, innate toughness is not observable, and so individuals make inferences about an individual's toughness from his actions. We show that, if social status is sufficiently important in criminal subcultures, there is a double divi-

of Quality of Life: Creating a More Civil City," Wednesday, February 24, 1998. http://www.nyc.gov/html/rwg/html/98a/quality.html 
dend of zero-tolerance in that it reduces both minor offenses and more severe crime.

The intuition behind this result is as follows. When minor offenses are punished harder, some individuals are deterred from committing those acts, and instead choose not to take action. Since these individuals are relatively 'gutless' individuals, the signaling value of committing a minor offense increases. This makes committing a minor offense attractive for some people who would otherwise commit more severe crime. If people in criminal subcultures care sufficiently about status, this effect dominates the standard positive substitution effect of zero-tolerance on more severe crime (Stigler 1970), and so stiffer penalties for minor offenses reduce crime across the board.

The paper is organized as follows. The next section discusses some stylized facts on status concerns and social norms in criminal subcultures and describes how the paper relates to the literature. Section 3 presents the model. Section 4 characterizes the equilibrium, Section 5 analyzes the effects of zero-tolerance, and Section 6 investigates the effects of penalizing severe crime. Section 7 concludes.

\section{Some stylized facts and related literature}

Recent studies in criminology, law, and economics have emphasized the role of social status and social norms in criminal behavior. Most of these studies consider negative stigma-effects of committing crime, and argue that stigma, in addition to imprisonment and fines, can be an important deterrent of criminal activity (e.g. Rasmusen (1996), Posner (2000), Bar-Gill and Harel (2001), Blume (2004), Funk (2004), and Arbak (2005)). While social norms that condemn criminal behavior are adhered to by a large part of the population, they are not universally shared. Indeed, in some subcultures, criminals are actually glorified. Meares, Katyal, and Kahan (2004) note that criminals "develop subnorms that may be antiethical to those of the law-abiding world. [...] The 
subnorms of this group reward the criminal activity that the law-abiding world punishes, and devalues the lawful alternatives that the law-abiding world celebrates." (pp. 1184-1185).

Street cultures are a case in point. Anderson (1999)'s ethnographic study Code of the Street on violence in Philadelphia's poor inner-city neighborhoods finds that residents are confronted with a "local hierarchy based on toughness" in which a reputation for being willing and able to fight earns respect among peers (p. 67). Based on interviews with 191 uncaught violent street offenders in St. Louis, Missouri, Topalli (2005) concludes that these offenders "operate in an environment in which oppositional norms catering to ethics of violence, toughness and respect dominate the social landscape" and that they "strive to protect a self-image consistent with a code of the streets orientation rather than a conventional one" (p. 797). Wilkinson (2001), in her study of violence in New York City, states that: " "toughness" has persistently been highly regarded, a source of considerable status among adolescents in a wide range of adolescent subcultures from street corner groups to gangs. [...] Violence often is used to perpetuate and refine the pursuit of "toughness," and to claim the identity of being among the toughest. [...] The status and reputations earned through violent means provide inner city adolescent males with positive feelings of self worth and "large" identities especially when other opportunities for identity development are not available." (pp. 231-233). ${ }^{2}$ Lastly, Matsueda et al. (2006a) test a rational choice model of theft and violence using data from the Denver Youth Survey. They find that "youth who expect to be seen as cool (and value being seen as cool) if they commit theft or violence tend to commit substantially more acts of theft and violence, on average, in the coming year." (p. 115). Matsueda et al. (2006b) obtain similar results using survey data from Seattle neighborhoods.

Our analysis is closely related to studies of social status, in particular to

\footnotetext{
${ }^{2}$ See also Fagan and Wilkinson (1998). Similar findings are reported by Hughes and Short (2005) studying street gangs in Chicago and by King (2001) discussing studies on violence among football fans in European countries.
} 
Bernheim (1994) and Bénabou and Tirole (2006). In Bernheim (1994), individuals conform to a standard of behavior so as to avoid being seen as having extreme preferences, which would reduce their status or popularity. In Bénabou and Tirole (2006), there is no such desire to resemble the mainstream. Instead, individuals want to signal their altruism and aim to appear as altruistic as possible. Likewise, in this paper, individuals who appear more 'tough' earn more respect from their peers. We share with these papers the focus on how external incentives may interfere with the desire to signal one's personality traits.

The idea that people may engage in costly signaling so as to gain esteem or acceptance by peers is also prominent in Austen-Smith and Fryer (2005). They develop a model in which individuals signal their social compatibility by underinvesting in education. ${ }^{3}$ Silverman (2004) studies a matching game with two-sided reputation in which some people directly benefit from violence, whereas others may participate in violence to acquire a 'street reputation,' which provides protection from future assault. One of his main results is that varying levels of participation in violence may be sustained by the same economic and social fundamentals. Further, he argues that the effects of enforcement policy may depend on how policy affects the visibility of a criminal action to peers, as visibility affects the reputational gain from crime.

Finally, our model is related to the broader literature in economics that links crimes with social norms and peer effects (see Van der Weele (2010) for an overview). These papers often consider rather reduced form models to represent social interactions. For example, Glaeser, Sacerdote, and Scheinkman (1996) and Patacchini and Zenou (2011) study models in which individuals want to minimize the social distance between their crime level and that of their reference group. These studies investigate the level of crime that arises from such interactions, and can be interpreted as a social norm of crime. Our study does not investigate the endogenous formation of norms, but simply assumes the

\footnotetext{
${ }^{3}$ Our study also relates to papers in which education signals ability, in particular to Bedard (2001) who argues that greater university access may reduce the signaling value of high school, and so may increase high school dropout rates.
} 
existence of a norm which places a value on being known as 'tough'. Given this norm, we consider a more specific mechanism for social interactions, based on signaling. This allows for a more complex analysis that includes spillover effects between different kinds of crime.

\section{The model}

Individuals choose between three possible actions denoted by $x \in\{0, m, e\}$, where $x=0$ represents abstaining from crime, $x=m$ represents committing a minor crime, and $x=e$ represents committing a severe crime. Apart from social status gains or losses, an individual who commits crime suffers an expected net utility loss of $c_{x}$. This expected net utility loss, which can be negative for some individuals, reflects among others the expected pecuniary gain or loss from crime, the risk of being arrested and punished, the risk of injury or death, and anticipated feelings of fear and guilt.

Individuals differ in innate 'toughness' $\sigma$ (a composite of nerve, physical fitness, insensitivity to guilt, and so on) and so expect a different net utility loss from committing a criminal act. Tougher individuals have higher $\sigma$ and face lower net cost of committing a crime: $c_{x}^{\prime}(\sigma)<0$ for $x=m$ and $x=e$. Besides an absolute advantage in both forms of crime, tougher individuals also have a comparative advantage in severe crime: $c_{e}^{\prime}(\sigma)<c_{m}^{\prime}(\sigma)$. We assume that $\sigma$ is distributed according to a $\operatorname{cdf} F(\sigma)$, with lower bound $\sigma_{l}$, upper bound $\sigma_{h}$, and density $f(\sigma)$. More specifically, we assume that

Assumption 1 The density $f(\sigma)$ is non-increasing everywhere.

This assumption says that there are relatively few tough types, which we take to be realistic. As we explain below, this assumption is necessary for some of our results. Moreover, as we show in the appendix, it guarantees stability of the equilibrium and uniqueness of the equilibrium thresholds. ${ }^{4}$

\footnotetext{
${ }^{4}$ In both instances this assumption is sufficient, but not necessary. That is, $f(\sigma)$ can be
} 
Individuals care about their social status for being tough. That is, an individual cares about other people's belief about his $\sigma$. People cannot observe each other's type, but they know the distribution of $\sigma$. They observe each other's actions, and update beliefs according to Bayes' rule. ${ }^{5}$ The posterior belief about an individual's $\sigma$ is denoted by $\widehat{\sigma}$. Since there are three possible actions $(0, m, e)$, an individual's $\widehat{\sigma}$ can take three values, which we denote by $\widehat{\sigma}_{0}$, $\widehat{\sigma}_{m}$, and $\widehat{\sigma}_{e}$. Following Bénabou and Tirole (2006), we assume that an individual's utility from social status depends linearly on the posterior belief about his type. Thus, the utility from social status is given by $s(\widehat{\sigma})$, with $s^{\prime}(\widehat{\sigma})>0$ and $s^{\prime \prime}(\widehat{\sigma})=0$. By the latter assumption, $s^{\prime}(\widehat{\sigma})$ is a constant and can be described as the weight on social status in the utility function.

\section{Equilibrium}

Throughout, we focus on a partially-separating Perfect Bayesian Equilibrium where some individuals abstain from crime, some commit a minor crime, and some commit a severe crime. Without loss of generality, we assume that if an individual is indifferent between actions, then he chooses the least severe crime. All proofs are in the appendix.

Let us first consider what happens when individuals do not care about their social status for being tough. Clearly, all individuals who expect a net utility loss from committing crime $\left(c_{x}(\sigma) \geq 0\right.$ for $x=m$ and $\left.x=e\right)$ abstain from crime. Individuals who expect a net utility gain from minor crime $\left(c_{m}(\sigma)<0\right)$ which is larger than or equal to the expected net utility gain from severe crime $\left(c_{m}(\sigma) \leq\right.$ $\left.c_{e}(\sigma)\right)$ commit a minor crime. Lastly, individuals expecting a net utility gain from severe crime $\left(c_{e}(\sigma)<0\right)$ which is larger than the expected net utility gain from minor crime $\left(c_{e}(\sigma)<c_{m}(\sigma)\right)$ commit a severe crime. Clearly, given

increasing on parts of the domain, as long as it does not increase 'too steeply' (which threatens equilibrium stability) or on a range that is 'too large' (which would invalidate Proposition 2).

${ }^{5}$ Silverman (2004) discusses evidence showing that a majority of violent crimes is committed in public. Also, many of the studies discussed in Section 2 stress the presence of peers when committing crime. 


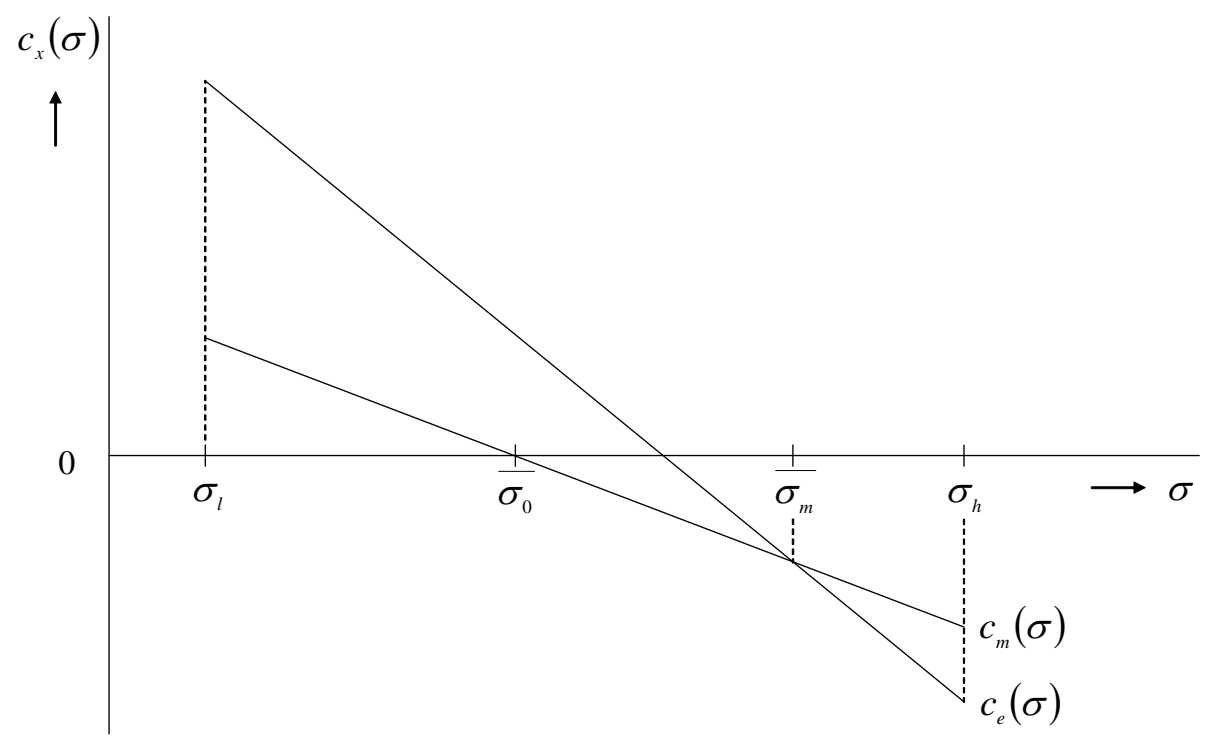

Figure 1: Crime in the absence of status concerns

that $\sigma_{l}$ is sufficiently low and $\sigma_{h}$ is sufficiently high, the assumption of absolute advantage $\left(c_{x}^{\prime}(\sigma)<0\right)$ implies that some people choose to abstain from crime whereas others choose to commit crime. If there exists a $\tilde{\sigma}$ such that $c_{e}(\widetilde{\sigma})=$ $c_{m}(\widetilde{\sigma}) \leq 0$, then the assumption of comparative advantage $\left(c_{e}^{\prime}(\sigma)<c_{m}^{\prime}(\sigma)\right)$ implies that among those who prefer crime some choose minor crime while others choose severe crime. Such a situation is depicted in Figure 1, where $\bar{\sigma}_{0}$ denotes the toughness of individuals at the margin between abstaining from crime and committing a minor crime and $\bar{\sigma}_{m}$ denotes the toughness of individuals at the margin between minor and severe crime. $^{6}$ Since tougher individuals have an

\footnotetext{
${ }^{6}$ Notice that if $c_{e}(\widetilde{\sigma})=c_{m}(\widetilde{\sigma})>0$, then all individuals who prefer committing a crime to abstaining from crime choose severe crime, and so nobody commits minor crime. Clearly, if
} 
absolute advantage in crime as well as a comparative advantage in severe crime $\left(c_{e}^{\prime}(\sigma)<c_{m}^{\prime}(\sigma)<0\right)$, the toughest individuals will commit severe crime while the least tough individuals will abstain from crime. A group in the middle will commit minor crime.

Crime in equilibrium when individuals care about their social status for being tough is described in the following Proposition.

Proposition 1 In an equilibrium where each action $x \in\{0, m, e\}$ is chosen by a strictly positive number of people, individuals committing severe crime enjoy highest status and individuals committing minor crime enjoy higher status than individuals who abstain from crime. Such an equilibrium exists if $\sigma_{l} \leq \bar{\sigma}_{0}<$ $\bar{\sigma}_{m}<\sigma_{h}$ where $\bar{\sigma}_{0}$ and $\bar{\sigma}_{m}$ are implicitly and uniquely defined by:

$$
\begin{aligned}
-c_{m}\left(\bar{\sigma}_{0}\right)+s\left(\widehat{\sigma}_{0}\right) & =s\left(\widehat{\sigma}_{m}\right), \\
-c_{m}\left(\bar{\sigma}_{m}\right)+s\left(\widehat{\sigma}_{m}\right) & =-c_{e}\left(\bar{\sigma}_{m}\right)+s\left(\widehat{\sigma}_{e}\right),
\end{aligned}
$$

and posterior beliefs are given by

$$
\widehat{\sigma}_{0}=\frac{\int_{\sigma_{l}}^{\bar{\sigma}_{0}} \sigma d F(\sigma)}{F\left(\bar{\sigma}_{0}\right)}<\widehat{\sigma}_{m}=\frac{\int_{\bar{\sigma}_{0}}^{\bar{\sigma}_{m}} \sigma d F(\sigma)}{F\left(\bar{\sigma}_{m}\right)-F\left(\bar{\sigma}_{0}\right)}<\widehat{\sigma}_{e}=\frac{\int_{\bar{\sigma}_{m}}^{\sigma_{h}} \sigma d F(\sigma)}{1-F\left(\bar{\sigma}_{m}\right)} .
$$

Proof: See Appendix.

Clearly, when crime is also motivated by a concern to signal one's toughness, some individuals who would otherwise abstain from crime commit minor crime. Even though, apart from status concerns, minor crime yields an expected net utility loss to these individuals, this is compensated by a gain in social status. Likewise, some individuals who would otherwise commit minor crime, choose severe crime instead so as to increase their social status. Social status concerns

the expected penalty for severe crime is sufficiently high compared to the expected penalty for minor crime, then $c_{e}(\widetilde{\sigma})=c_{m}(\widetilde{\sigma}) \leq 0$. This can also be seen from Figure 1 by noticing that an increase in the expected penalty for severe crime shifts the $c_{e}(\sigma)$-curve upwards. Likewise, an increase in the expected penalty for minor crime shifts the $c_{m}(\sigma)$-curve upwards. 
thus induce more people to commit crime. Moreover, among those who commit crime, more people commit severe crime than when social status plays no role.

\section{Double dividend of zero-tolerance}

This section examines the effects of a more aggressive enforcement of minor crime (zero-tolerance) on minor and severe crime. Zero-tolerance may take the form of an increase in the probability of punishment for minor crime or an increase in the punishment for minor crime itself. Recall that the expected net utility loss from crime, $c_{x}(\sigma)$, includes the risk and severity of punishment. Hence, zero-tolerance can be represented by an increase in $c_{m}(\sigma)$ for all $\sigma$. Clearly, in the absence of status concerns, this gives rise to two effects. First, it induces some individuals to abstain from crime rather than to commit minor crime. Second, it gives rise to a substitution between types of crime as in Stigler (1970): some individuals choose severe crime rather than minor crime. ${ }^{7}$ Hence, in the absence of status concerns, zero-tolerance decreases minor crime and increases severe crime. Because of social status concerns, the last effect may be reversed, and so zero-tolerance may yield a double dividend. This is shown in the following Proposition.

\section{Proposition 2 Zero-tolerance of minor crimes}

1. always decreases the number of people committing minor crime,

2. decreases the number of people committing severe crime if

$$
s^{\prime}\left(\widehat{\sigma}_{0}\right) \frac{d \widehat{\sigma}_{0}}{d \bar{\sigma}_{0}}>-c_{m}^{\prime}\left(\bar{\sigma}_{0}\right)
$$

\footnotetext{
${ }^{7}$ This can also be seen from Figure 1 by noting that a stiffer penalty for minor crime shifts the $c_{m}(\sigma)$-curve upwards and hence increases $\bar{\sigma}_{0}$ and decreases $\bar{\sigma}_{m}$, implying a decrease in the number of people committing minor crime and an increase in the number of people committing severe crime.
} 
that is, if the weight on social status in the utility function is sufficiently high.

Proof: See Appendix.

The intuition behind Proposition 2 relies on the interplay between the policy and status in equilibrium. Given people's beliefs $\left(\widehat{\sigma}_{0}, \widehat{\sigma}_{m}\right.$, and $\left.\widehat{\sigma}_{e}\right)$, zerotolerance induces some people to abstain from crime rather than to commit minor crime. Since these individuals are relatively 'gutless' individuals (that is, have relatively low toughness), the social status gained through committing minor crime increases. This makes minor crime more attractive for individuals at the margin between minor and severe crime, and so gives them an incentive to choose minor crime. Severe crime decreases if this extra status from minor crime outweighs the extra costs imposed by zero-tolerance for individuals at the margin between minor and severe crime. The condition for this to happen is that people in criminal subcultures must care enough about social status $\left(s^{\prime}(\widehat{\sigma})\right.$ should be sufficiently high). Moreover, the deterrent effect of zero-tolerance at the lower ends of the toughness distribution must be sufficiently large, which happens if costs decreases slowly with type $\left(-c_{m}^{\prime}\left(\bar{\sigma}_{0}\right)>0\right.$ is low $)$ and the status of inaction increases enough when the threshold $\bar{\sigma}_{0}$ rises $\left(\frac{d \widehat{\sigma}_{0}}{d \bar{\sigma}_{0}}\right.$ is high). The reason is that if more individuals at the margin between inaction and minor crime switch to inaction, then the increase in the signaling value of minor crime in response to zero-tolerance is larger.

With respect to the fraction of people committing minor crime, conflicting forces are at work. Some gutless individuals will be deterred from minor crime, whereas some tough individuals may now be attracted to it. The proposition shows that the former effect outweighs the latter, and minor crime decreases. Note that this result relies on Assumption 1 that $f(\sigma)$ is non-increasing. The intuition is that if there are relatively few tough types, a small change in the threshold $\bar{\sigma}_{m}$ has a large effect on the relative status of minor and severe crimes. Thus, a relatively small number of people switching from severe to minor crime 
will restore equilibrium. This amount will not offset the number of gutless people switching from minor crime to no crime.

Hence, if the condition in Proposition 2 is satisfied, zero-tolerance leads to a double dividend and reduces both the number of individuals committing severe crime and the number of people committing minor crime.

\section{Fighting severe crime}

This section studies the effects of stiffer penalties for severe crime.

Proposition 3 An increase in the penalty for severe crimes

1. always increases minor crime,

2. always decreases severe crime,

3. always increases the total number of people committing crime.

Proof: See Appendix.

By now, the reader will probably find the intuition for these results straightforward. Through a standard substitution effect, stiffer penalties for severe crime induce some individuals at the margin between severe and minor crime to commit minor rather than severe crime. Since these individuals are relatively tough, this raises status when committing a minor crime compared to status when being passive, and thus induces individuals at the margin between minor crime and inaction to commit minor crime. It follows from Proposition 3 that if minor crime is sufficiently costly to society, the total cost of crime may actually increase as a result of higher penalties on severe crime. Moreover, if deterrence of minor crimes yields a double dividend, this policy may deliver more 'bang for the buck' than deterrence of severe crime. 


\section{Concluding remarks}

We have studied the effects of law enforcement when crime is, at least partly, motivated by social status concerns. We have shown that, when status concerns are sufficiently important, zero-tolerance may yield a double dividend in that it reduces both minor crime as well as more severe crime. The intuition behind this result is that, by deterring some relatively gutless people, being tough on minor crime makes minor crime a tougher act, and so it becomes more attractive for some people who would otherwise commit more severe crime. Obviously, an alternative way to reduce crime across the board is to increase the penalties for both minor and severe crime. It is straightforward to verify that, in our model, such a policy can simultaneously reduce minor and severe crime. However, increasing penalties across the board may not always be optimal or feasible. One reason is that zero-tolerance policies may be less costly than e.g. longer terms of imprisonment for severe crime (Kahan (1997)). Another reason is that some forms of punishment may be considered immoral, which puts a limit on the harshness of punishment of severe crimes.

We have restricted the analysis by assuming that individuals can only take one of three actions: abstaining from crime, committing a minor crime, and committing a severe crime. While this is clearly a restrictive assumption, the resulting status hierarchy consisting of three broad groups is well in line with the findings in Fagan and Wilkinson (1998)'s empirical study of violent events in New York City. Based on narrative reconstructions of violent events reported by 125 young men, they find a hierarchy of social identities consisting of three broad types with 'wild' individuals (who have performed extraordinary acts of violence) at the top, 'cool' individuals (who do what it takes in 'heated' situations) in the middle, and 'herbs' (who cannot fight or do not prove their toughness) at the bottom of the status hierarchy. Clearly, extending the model to allow for a richer, continuous action space will result in a larger number social identities arising in equilibrium. We speculate that such a model would feature a perfectly separating equilibrium, with (depending on the size of the action 
space) pooling of the toughest individuals on the highest level of crime. We believe that our insights would remain true in such a model. That is, increasing punishment for a particular range of crimes may reduce the incidence of crimes of higher levels, and will increase crimes at the level below that range.

In line with the evidence cited in Section 2, we have assumed that individuals care directly about status. It is easy to think of alternative interpretations, though, where status is a means to obtain e.g. protection, attention, or sex. Anderson (1999), Bandiera (2003), and Silverman (2004) stress the importance of acquiring a reputation for being tough so as to protect oneself or others against future attacks. Dnes and Garoupa (2010) argue that violent acts by youngsters are investments in social status necessary to be recruited by gang leaders. Relatedly, in Poutvaara and Priks (2009)'s model of hooligan groups, some of the members fight so as to retain the social benefits from being part of the group. Wilkinson (2001) finds in her sample of young men in New York City that "criminals and those who exhibit tough qualities and behavior are the "populars" and get the most attention from others." (p. 241). Drawing on literature from evolutionary psychology and biology, Rebellon and Manasse (2004) argue that criminal behavior by males may signal positive adaptive qualities like nerve and bravery and so may attract females. Using US panel data, they find some evidence for a causal effect of delinquency on romantic involvement (see also Palmer and Tilley (1995)).

Critical for our results is the assumption that people in criminal subcultures care about their social status for being 'tough.' In Section 2, we discussed several studies stressing the relevance of status hierarchies based on toughness and the prevalence of anti-ethical norms in a wide range of subcultures. An important question that we did not deal with in this paper is how such norms and subcultures come into being and evolve over time? Empirical studies suggest that a lack of alternative opportunities for identity development may be responsible (e.g. Wilkinson (2001)). Work along the lines of Oxoby (2004) may shed more light on this important issue as well as on the implications for optimal enforcement policies of endogenous formation of subcultures and norms. 
Finally, if our assumptions are not valid, the policy implications highlighted in this paper may not hold. For example, Poutvaara and Priks (2011) model the distinction between minor and severe crime in the context of a gang structure, in which the gang leader sets the optimal crime levels for the gang members. In their model, penalties for minor crime will never decrease severe crime, but may increase it. O'Flaherty and Sethi (2010) show that a reputation for toughness may not be a valuable asset in all circumstances. They argue that blacks are more likely to be murdered because they are perceived as more violent. This inspires fear, which raises the possibility of escalation of conflicts and the use of preemptive violence against blacks. 


\section{Appendix}

Proof of Proposition 1. Given the posterior beliefs $\left(\widehat{\sigma}_{0}, \widehat{\sigma}_{m}, \widehat{\sigma}_{e}\right)$, individual $i$ prefers $x=m$ to $x=0$ if:

$$
-c_{m}\left(\sigma_{i}\right)+s\left(\widehat{\sigma}_{m}\right)>s\left(\widehat{\sigma}_{0}\right)
$$

From $c_{m}^{\prime}(\sigma)<0$ (absolute advantage), it follows that if individual $i$ prefers action $x=m$ to action $x=0$, then all individuals with $\sigma \geq \sigma_{i}$ prefer action $x=m$ to action $x=0$, and vice versa. Denote by $\bar{\sigma}_{0}$ the value of $\sigma_{i}$ for which (A1) holds with equality. Clearly, in an equilibrium where some people abstain from crime it must hold that $\bar{\sigma}_{0} \geq \sigma_{l}$.

Given the posterior beliefs $\left(\widehat{\sigma}_{0}, \widehat{\sigma}_{m}, \widehat{\sigma}_{e}\right)$, individual $i$ prefers $x=m$ to $x=e$ if:

$$
-c_{m}\left(\sigma_{i}\right)+s\left(\widehat{\sigma}_{m}\right) \geq-c_{e}\left(\sigma_{i}\right)+s\left(\widehat{\sigma}_{e}\right)
$$

From $c_{e}^{\prime}(\sigma)<c_{m}^{\prime}(\sigma)$ (comparative advantage), it follows that if individual $i$ prefers action $x=m$ to action $x=e$, then all individuals with $\sigma \leq \sigma_{i}$ prefer action $x=m$ to action $x=e$, and vice versa. Denote by $\bar{\sigma}_{m}$ the value of $\sigma_{i}$ for which (A2) holds with equality. Clearly, in an equilibrium where some people choose to commit severe crime it must hold that $\bar{\sigma}_{m}<\sigma_{h}$.

From (A1) and (A2) and our assumptions on absolute and comparative advantage, it follows that an equilibrium where some people choose to commit minor crime must have $\bar{\sigma}_{0}<\bar{\sigma}_{m}$.

Hence, if $\sigma_{l} \leq \bar{\sigma}_{0}<\bar{\sigma}_{m}<\sigma_{h}$, the posterior beliefs in equilibrium are given by:

$$
\widehat{\sigma}_{0}=\frac{\int_{\sigma_{l}}^{\bar{\sigma}_{0}} \sigma d F(\sigma)}{F\left(\bar{\sigma}_{0}\right)}<\widehat{\sigma}_{m}=\frac{\int_{\bar{\sigma}_{0}}^{\bar{\sigma}_{m}} \sigma d F(\sigma)}{F\left(\bar{\sigma}_{m}\right)-F\left(\bar{\sigma}_{0}\right)}<\widehat{\sigma}_{e}=\frac{\int_{\bar{\sigma}_{m}}^{\sigma_{h}} \sigma d F(\sigma)}{1-F\left(\bar{\sigma}_{m}\right)}
$$

In such an equilibrium, it follows from $s^{\prime}(\widehat{\sigma})>0$ that $s\left(\widehat{\sigma}_{0}\right)<s\left(\widehat{\sigma}_{m}\right)<s\left(\widehat{\sigma}_{e}\right)$ and status increases with the severity of the crime. 
Following the definition above, $\bar{\sigma}_{0}$ and $\bar{\sigma}_{m}$ are given by:

$$
\begin{aligned}
-c_{m}\left(\bar{\sigma}_{0}\right)+s\left(\widehat{\sigma}_{m}\right) & =s\left(\widehat{\sigma}_{0}\right), \\
-c_{m}\left(\bar{\sigma}_{m}\right)+s\left(\widehat{\sigma}_{m}\right) & =-c_{e}\left(\bar{\sigma}_{m}\right)+s\left(\widehat{\sigma}_{e}\right) .
\end{aligned}
$$

Thus, if the solutions to these equations for $\bar{\sigma}_{0}$ and $\bar{\sigma}_{m}$ satisfy $\sigma_{l} \leq \bar{\sigma}_{0}<$ $\bar{\sigma}_{m}<\sigma_{h}$, then an equilibrium exists in which each action $x \in\{0, m, e\}$ is chosen by a strictly positive number of people.

Finally, to guarantee the uniqueness of the thresholds $\bar{\sigma}_{0}$ and $\bar{\sigma}_{m}$ and the stability of the equilibrium, we need to do some extra work. We define

$$
\begin{aligned}
\delta_{0}\left(\bar{\sigma}_{0}, \bar{\sigma}_{m}\right) & \equiv s\left(\widehat{\sigma}_{m}\left(\bar{\sigma}_{m}, \bar{\sigma}_{0}\right)\right)-s\left(\widehat{\sigma}_{0}\left(\bar{\sigma}_{0}\right)\right) \quad \text { and } \\
\delta_{m}\left(\bar{\sigma}_{0}, \bar{\sigma}_{m}\right) & \equiv s\left(\widehat{\sigma}_{e}\left(\bar{\sigma}_{m}\right)\right)-s\left(\widehat{\sigma}_{m}\left(\bar{\sigma}_{m}, \bar{\sigma}_{0}\right)\right),
\end{aligned}
$$

which represent the gain in status for threshold types $\bar{\sigma}_{0}$ and $\bar{\sigma}_{m}$ respectively from switching to a higher level of crime.

It is easy to show that if $\delta_{0}$ or $\delta_{m}$ decrease faster than the costs of crime, one can obtain multiple equilibrium thresholds. Some of these are unstable equilibria in which a) the threshold types are indifferent between different crime levels but b) the slightest 'tremble' in the threshold level will cause the equilibrium to unravel. Let $\delta_{00}\left(\bar{\sigma}_{0}, \bar{\sigma}_{m}\right) \equiv \frac{d \delta_{0}\left(\bar{\sigma}_{0}, \bar{\sigma}_{m}\right)}{d \bar{\sigma}_{0}}$ and similarly $\delta_{m m}\left(\bar{\sigma}_{0}, \bar{\sigma}_{m}\right) \equiv \frac{d \delta_{m}\left(\bar{\sigma}_{0}, \bar{\sigma}_{m}\right)}{d \bar{\sigma}_{m}}$. The following conditions rule out these equilibria and assure that the threshold levels $\bar{\sigma}_{0}$ and $\bar{\sigma}_{m}$ are unique

$$
\begin{aligned}
c_{m}^{\prime}\left(\bar{\sigma}_{0}\right)<\delta_{00}\left(\bar{\sigma}_{0}, \bar{\sigma}_{m}\right) & \forall \bar{\sigma}_{0}, \bar{\sigma}_{m} \text { s.t. } \bar{\sigma}_{0}<\bar{\sigma}_{m}, \quad \text { and } \\
c_{e}^{\prime}\left(\bar{\sigma}_{m}\right)-c_{m}^{\prime}\left(\bar{\sigma}_{m}\right)<\delta_{m m}\left(\bar{\sigma}_{0}, \bar{\sigma}_{m}\right) & \forall \bar{\sigma}_{0}, \bar{\sigma}_{m} \text { s.t. } \bar{\sigma}_{0}<\bar{\sigma}_{m} .
\end{aligned}
$$

In general, the shape of the functions $\delta_{0}$ and $\delta_{m}$ will depend on shape of the density $f$. Jewitt (2004) (see also Bénabou and Tirole 2006: proposition 6.1 on page 1667$)$ shows that if the density $f(\sigma)$ is weakly decreasing everywhere, then $\delta_{0}$ and $\delta_{m}$ are weakly increasing. Thus, a weakly decreasing $f(\sigma)$ is a sufficient 
(although not necessary) condition for equations (A4) and (A5) to hold.

Proof of Proposition 2. We consider the effects of increasing the expected net utility loss from minor crime by $\mu$ for all types. The equilibrium values of $\bar{\sigma}_{0}$ and $\bar{\sigma}_{m}$ become:

$$
\begin{aligned}
-c_{m}\left(\bar{\sigma}_{0}\right)-\mu+s\left(\widehat{\sigma}_{m}\right) & =s\left(\widehat{\sigma}_{0}\right), \\
-c_{m}\left(\bar{\sigma}_{m}\right)-\mu+s\left(\widehat{\sigma}_{m}\right) & =-c_{e}\left(\bar{\sigma}_{m}\right)+s\left(\widehat{\sigma}_{e}\right),
\end{aligned}
$$

where $\widehat{\sigma}_{0}, \widehat{\sigma}_{m}$, and $\widehat{\sigma}_{e}$ are functions of $\bar{\sigma}_{0}$ and $\bar{\sigma}_{m}$ as described by (A3). Applying the implicit function theorem, we obtain after some rewriting:

$$
\begin{aligned}
\frac{d \bar{\sigma}_{0}}{d \mu} & =-\frac{c_{e}^{\prime}\left(\bar{\sigma}_{m}\right)-c_{m}^{\prime}\left(\bar{\sigma}_{m}\right)-\delta_{m m}\left(\bar{\sigma}_{0}, \bar{\sigma}_{m}\right)-s^{\prime}\left(\widehat{\sigma}_{m}\right) \frac{d \widehat{\sigma}_{m}}{d \bar{\sigma}_{m}}}{\left[c_{e}^{\prime}\left(\bar{\sigma}_{m}\right)-c_{m}^{\prime}\left(\bar{\sigma}_{m}\right)-\delta_{m m}\left(\bar{\sigma}_{0}, \bar{\sigma}_{m}\right)\right]\left[c_{m}^{\prime}\left(\bar{\sigma}_{0}\right)-\delta_{00}\left(\bar{\sigma}_{0}, \bar{\sigma}_{m}\right)\right]+\frac{\left(s^{\prime}\left(\widehat{\sigma}_{m}\right) d \widehat{\sigma}_{m}\right)^{2}}{d \bar{\sigma}_{0} d \bar{\sigma}_{m}}},\left(\begin{array}{c}
(\mathrm{A} 6) \\
\frac{d \bar{\sigma}_{m}}{d \mu}=\frac{c_{m}^{\prime}\left(\bar{\sigma}_{0}\right)-\delta_{00}\left(\bar{\sigma}_{0}, \bar{\sigma}_{m}\right)+s^{\prime}\left(\widehat{\sigma}_{m}\right) \frac{d \widehat{\sigma}_{m}}{d \bar{\sigma}_{0}}}{\left[c_{e}^{\prime}\left(\bar{\sigma}_{m}\right)-c_{m}^{\prime}\left(\bar{\sigma}_{m}\right)-\delta_{m m}\left(\bar{\sigma}_{0}, \bar{\sigma}_{m}\right)\right]\left[c_{m}^{\prime}\left(\bar{\sigma}_{0}\right)-\delta_{00}\left(\bar{\sigma}_{0}, \bar{\sigma}_{m}\right)\right]+\frac{\left(s^{\prime}\left(\widehat{\sigma}_{m}\right) d \widehat{\sigma}_{m}\right)^{2}}{d \bar{\sigma}_{0} d \bar{\sigma}_{m}}}
\end{array}\right.
\end{aligned}
$$

From (A3) we can derive

$$
\begin{aligned}
\frac{d \widehat{\sigma}_{0}}{d \bar{\sigma}_{0}} & =\frac{f\left(\bar{\sigma}_{0}\right)}{F\left(\bar{\sigma}_{0}\right)}\left[\bar{\sigma}_{0}-\widehat{\sigma}_{0}\right] \\
\frac{d \widehat{\sigma}_{m}}{d \bar{\sigma}_{0}} & =\frac{f\left(\bar{\sigma}_{0}\right)}{F\left(\bar{\sigma}_{m}\right)-F\left(\bar{\sigma}_{0}\right)}\left[\widehat{\sigma}_{m}-\bar{\sigma}_{0}\right] \\
\frac{d \widehat{\sigma}_{m}}{d \bar{\sigma}_{m}} & =\frac{f\left(\bar{\sigma}_{m}\right)}{F\left(\bar{\sigma}_{m}\right)-F\left(\bar{\sigma}_{0}\right)}\left[\bar{\sigma}_{m}-\widehat{\sigma}_{m}\right]
\end{aligned}
$$

First, the sign of the change in the fraction of people committing severe crime is given by the sign of (A7). By (A4) and (A5) we know that the denominator 
of (A7) is positive. The numerator is positive if:

$$
c_{m}^{\prime}\left(\bar{\sigma}_{0}\right)-\delta_{00}\left(\bar{\sigma}_{0}, \bar{\sigma}_{m}\right)+s^{\prime}\left(\widehat{\sigma}_{0}\right) \frac{d \widehat{\sigma}_{m}}{d \bar{\sigma}_{0}}>0
$$

Using the definition of $\delta_{0}\left(\bar{\sigma}_{0}, \bar{\sigma}_{m}\right)$, this can be rewritten as

$$
s^{\prime}\left(\widehat{\sigma}_{0}\right) \frac{d \widehat{\sigma}_{0}}{d \bar{\sigma}_{0}}>-c_{m}^{\prime}\left(\bar{\sigma}_{0}\right)
$$

which is identical to the condition in Proposition 2.

Second, the change in the fraction of people committing minor crime is

$$
\frac{d\left[F\left(\bar{\sigma}_{m}\right)-F\left(\bar{\sigma}_{0}\right)\right]}{d \mu}=f\left(\bar{\sigma}_{m}\right) \frac{d \bar{\sigma}_{m}}{d \mu}-f\left(\bar{\sigma}_{0}\right) \frac{d \bar{\sigma}_{0}}{d \mu}
$$

Substituting (A6) and (A7), and using conditions (A4) and (A5) it is easy to show that this expression is negative if and only if

$$
f\left(\bar{\sigma}_{m}\right) s^{\prime}\left(\widehat{\sigma}_{m}\right) \frac{d \widehat{\sigma}_{m}}{d \bar{\sigma}_{0}} \leq f\left(\bar{\sigma}_{0}\right) s^{\prime}\left(\widehat{\sigma}_{0}\right) \frac{d \widehat{\sigma}_{m}}{d \bar{\sigma}_{m}}
$$

Substituting (A9) and (A10) into (A12) and using $s^{\prime}\left(\widehat{\sigma}_{0}\right)=s^{\prime}\left(\widehat{\sigma}_{m}\right)=s$ we find that the number of people who commit minor crime decreases with $\mu$ if and only if

$$
\widehat{\sigma}_{m} \leq \frac{\bar{\sigma}_{0}+\bar{\sigma}_{m}}{2}
$$

It is immediate that this is satisfied if the density is non-increasing everywhere.

Proof of Proposition 3. Consider the effect of increasing the individual's cost of committing a severe crime by $\varepsilon$ for all types. Thus, the implicit functions 
for the equilibrium values of $\bar{\sigma}_{0}$ and $\bar{\sigma}_{m}$ become:

$$
\begin{aligned}
-c_{m}\left(\bar{\sigma}_{0}\right)+s\left(\widehat{\sigma}_{m}\right) & =s\left(\widehat{\sigma}_{0}\right), \\
-c_{m}\left(\bar{\sigma}_{m}\right)+s\left(\widehat{\sigma}_{m}\right) & =-c_{e}\left(\bar{\sigma}_{m}\right)-\varepsilon+s\left(\widehat{\sigma}_{e}\right),
\end{aligned}
$$

where $\widehat{\sigma}_{0}, \widehat{\sigma}_{m}$, and $\widehat{\sigma}_{e}$ are functions of $\bar{\sigma}_{0}$ and $\bar{\sigma}_{m}$ given by (A3). Totally differentiating with respect to $\bar{\sigma}_{0}, \bar{\sigma}_{m}$, and $\varepsilon$ yields after some rewriting:

$$
\begin{aligned}
\frac{d \bar{\sigma}_{0}}{d \varepsilon} & =\frac{-s^{\prime}\left(\widehat{\sigma}_{m}\right) \frac{d \widehat{\sigma}_{m}}{d \bar{\sigma}_{m}}}{\left[c_{e}^{\prime}\left(\bar{\sigma}_{m}\right)-c_{m}^{\prime}\left(\bar{\sigma}_{m}\right)-\delta_{m m}\left(\bar{\sigma}_{0}, \bar{\sigma}_{m}\right)\right]\left[c_{m}^{\prime}\left(\bar{\sigma}_{0}\right)-\delta_{00}\left(\bar{\sigma}_{0}, \bar{\sigma}_{m}\right)\right]+\frac{\left(s^{\prime}\left(\widehat{\sigma}_{m}\right) d \widehat{\sigma}_{m}\right)^{2}}{d \bar{\sigma}_{0} d \bar{\sigma}_{m}}}<0, \\
\frac{d \bar{\sigma}_{m}}{d \varepsilon} & =\frac{-\left[c_{m}^{\prime}\left(\bar{\sigma}_{0}\right)-\delta_{00}\left(\bar{\sigma}_{0}, \bar{\sigma}_{m}\right)\right]}{\left[c_{e}^{\prime}\left(\bar{\sigma}_{m}\right)-c_{m}^{\prime}\left(\bar{\sigma}_{m}\right)-\delta_{m m}\left(\bar{\sigma}_{0}, \bar{\sigma}_{m}\right)\right]\left[c_{m}^{\prime}\left(\bar{\sigma}_{0}\right)-\delta_{00}\left(\bar{\sigma}_{0}, \bar{\sigma}_{m}\right)\right]+\frac{\left(s^{\prime}\left(\widehat{\sigma}_{m}\right) d \widehat{\sigma}_{m}\right)^{2}}{d \bar{\sigma}_{0} d \bar{\sigma}_{m}}}>0,
\end{aligned}
$$

where we used (A4) and (A5) to establish the signs of these expressions. The proof of part 3 follows directly from (A14). 


\section{References}

[1] Anderson, Elijah (1999), Code of the Street, New York: Norton.

[2] Arbak, Emrah (2005), Social Status and Crime, GATE Working Paper 05-10, Université Lyon 2.

[3] Austen-Smith, David and Roland G. Fryer, Jr. (2005), An Economic Analysis of "Acting White", Quarterly Journal of Economics, 120(2): 551-583.

[4] Bandiera, Oriana (2003), Land Reform, the Market for Protection, and the Origins of the Sicilian Mafia: Theory and Evidence, Journal of Law, Economics, and Organization, 19(1): 218-244.

[5] Bar-Gill, Oren and Alon Harel (2001), Crime Rates and Expected Sanctions: The Economics of Deterrence Revisited, Journal of Legal Studies, 30(2): 485-501.

[6] Bedard, Kelly (2001), Human Capital versus Signaling Models: University Access and High School Dropouts, Journal of Political Economy, 109(4): 749-775.

[7] Bénabou, Roland and Jean Tirole (2006), Incentives and Prosocial Behavior, American Economic Review, 96(5): 1652-1678.

[8] Bernheim, B. Douglas (1994), A Theory of Conformity, Journal of Political Economy, 102(5): 841-877.

[9] Blume, Lawrence (2004), Stigma and Social Control, Mimeo, Cornell University.

[10] Braga, Anthony A., David L. Weisburd, Elin J. Waring, Lorraine Green Mazerolle, William Spelman, and Francis Gajewski (1999), ProblemOriented Policing in Violent Crime Places: A Randomized Controlled Experiment, Criminology, 37(3): 541-580.

[11] Corman, Hope and Naci Mocan (2005), Carrots, Sticks and Broken Windows, Journal of Law and Economics, 48(1): 235-266.

[12] Dnes, Antony W. and Nuno Garoupa (2010), Behavior, Human Capital and the Formation of Gangs, Kyklos, 63(4): 517-529. 
[13] Fagan, Jeffrey, and Deanna Wilkinson (1998), Guns, Youth Violence, and Social Identity in Inner Cities, Crime and Justice: A Review of Research, 24: $105-188$.

[14] Ferrer, Rosa (2010), Breaking the Law when Others Do: A Model of Law Enforcement with Neighborhood Externalities, European Economic Review. 54: 163-180.

[15] Funk, Patricia (2004), On the Effective Use of Stigma as a Crime-deterrent, European Economic Review, 48(4): 715-728.

[16] Funk, Patricia and Peter Kugler (2003), Dynamic Interactions between Crimes, Economics Letters, 79(3): 291-298.

[17] Glaeser, Edward L., Bruce Sacerdote and José A. Scheinkman (1996), Crime and Social Interactions, Quarterly Journal of Economics, 111(2): 507-548.

[18] Harcourt, Bernard E. and Jens Ludwig (2006), Broken Windows: New Evidence from New York City and a Five-City Social Experiment, University of Chicago Law Review, 73(1): 271-320.

[19] Hughes, Lorine A. and James F. Short, Jr. (2005), Disputes Involving Youth Street Gang Members: Micro-Social Contexts, Criminology, 43(1): 43-76.

[20] Jewitt, Ian (2004), Notes on the Shape of Distributions. Mimeo, Oxford University.

[21] Kahan, Dan M. (1997), Social Influence, Social Meaning, and Deterrence, Virginia Law Review, 83: 349-395.

[22] King, Anthony (2001), Violent Pasts: Collective Memory and Football Hooliganism, Sociological Review, 49(3): 568-585.

[23] Kubrin, Charis E., Steven F. Messner, Glenn Deane, Kelly McGeever, Thomas D. Stucky (2010), Proactive Policing and Robbery Rates Across U.S. Cities, Criminology, 48(1): 57-97.

[24] Levitt, Steven D. (2004), Understanding Why Crime Fell in the 1990s: Four Factors that Explain the Decline and Six that Do Not, Journal of Economic Perspectives, 18(1): 163-190. 
[25] Lochner, Lance (2007), Individual Perceptions of the Criminal Justice System, American Economic Review, 97(1): 444-460.

[26] MacDonald, John M. (2002), The Effectiveness of Community Policing in Reducing Urban Violence, Crime \& Delinquency, 48(4): 592-618.

[27] Matsueda, Ross L., Derek A. Kreager, and David Huizinga (2006a), Deterring Delinquents: A Rational Choice Model of Theft and Violence, American Sociological Review, 71(1): 95-122.

[28] Matsueda, Ross L., Kevin Drakulich, and Charis E. Kubrin (2006b), Race and Neighborhood Codes of Violence, In: Ruth D. Peterson, Lauren J. Krivo, and John Hagan (Eds.), The Many Colors of Crime: Inequalities of Race, Ethnicity, and Crime in America, New York University Press.

[29] Meares, Tracey L., Neal Katyal, and Dan M. Kahan (2004), Updating the Study of Punishment, Stanford Law Review, 56: 1171-1210.

[30] O'Flaherty, Brendan and Rajiv Sethi (2010), Homicide in Black and White, Journal of Urban Economics, 68(3): 215-230.

[31] Oxoby, Robert J. (2004), Cognitive Dissonance, Status and Growth of the Underclass, Economic Journal, 114: 727-749.

[32] Palmer, Craig T. and Christopher F. Tilley (1995), Sexual Access to Females as a Motivation for Joining Gangs: An Evolutionary Approach, Journal of Sex Research, 32(3): 213-217.

[33] Patacchini, Eleonora and Yves Zenou (2011), Juvenile Delinquency and Conformism, Journal of Law, Economics and Organization, forthcoming.

[34] Posner, Eric A. (2000), Law and Social Norms, Cambridge, MA: Harvard University Press.

[35] Poutvaara, Panu and Mikael Priks (2009), Hooliganism and Police Tactics, Journal of Public Economic Theory, 11(3): 441-453.

[36] Poutvaara, Panu and Mikael Priks (2011), Unemployment and Gang Crime: Could Prosperity Backfire?, Economics of Governance, fortcoming. 
[37] Rasmusen, Eric (1996), Stigma and Self-fulfilling Expectations of Criminality, Journal of Law and Economics, 39(2): 519-544.

[38] Rebellon, Cesar J. and Michelle Manasse (2004), Do "Bad Boys" Really Get the Girls? Delinquency as a Cause and Consequence of Dating Behavior Among Adolescents, Justice Quarterly, 21(2): 355-389.

[39] Rosado, Caleb (2008), Context Determines Content: Quantum Physics as a Framework for 'Wholeness' in Urban Transformation, Urban Studies, 45(10): 2075-2097.

[40] Sampson, Robert J. and Jacqueline Cohen (1988), Deterrent Effects of the Police on Crime: A Replication and Theoretical Extension, Law and Society Review, 22: 163-189.

[41] Sampson, Robert J. and Stephen W. Raudenbush (2004), Seeing Disorder: Neighborhood Stigma and the Social Construction of 'Broken Windows', Social Psychology Quarterly, 67(4): 319-342.

[42] Silverman, Dan (2004), Street Crime and Street Culture, International Economic Review, 45(3): 761-786.

[43] Stigler, George, (1970), The Optimum Enforcement of Laws, Journal of Political Economy, 78(3): 526-536.

[44] Topalli, Volkan (2005), When Being Good is Bad: An Expansion of Neutralization Theory, Criminology, 43(3): 797-835.

[45] Van der Weele, Joël J. (2010), Beyond the State of Nature: Introducing Social Interactions into the Economic Model of Crime, SSRN Working Paper no. 1655323.

[46] Vollaard, Ben (2006), Evaluating the Push for Tougher, More Targeted Policing in the Netherlands, CPB Document No. 119.

[47] Weisburd, David and John E. Eck (2004), What Can Police Do to Reduce Crime, Disorder, and Fear?, Annals of the American Academy of Political and Social Sciences, 593(1): 42-65.

[48] Wilkinson, Deanna (2001), Violent Events and Social Identity: Specifying the Relationship between Respect and Masculinity in Inner-City Youth Violence, Sociological Studies of Children and Youth, 8: 231-265. 
[49] Wilson, James Q. and George Kelling (1982), Broken Windows: The Police and Neighborhood Safety, Atlantic Monthly, 249(3): 29-38. 